\title{
My Mother, My Role Model: Mother's Influence on Women's Fertility Intention in Indonesia
}

\author{
Purnama Cahya Sari Silalahi ${ }^{a}$ \\ Diahhadi Setyonalurib \\ Universitas Indonesia
}

\begin{abstract}
The literature shows that children born in a large family tend to adopt the same family norm as their parents. This similarity may occur because values, norms, as well as reproductive behaviours are transmitted from parents to their offspring whereby this transmission may determine the fertility rate. For Indonesia, given that the family planning program has successfully halved the fertility rate, yet for the last decade, it remains at 2.6 children per woman. Such phenomenon shows that even though most women have adopted small family norm, but a sizeable share continue to have more than two children. This study aims to examine the effect of mother's fertility behaviour on woman's reproductive intention. Ever-married women aged 15-49 years old in 2014 who have information about their biological mother are analysed by using data from Indonesian Family Life Survey. Zero-inflated Poisson regression model is used to estimate the transmission effect. The sample is stratified by parity. The results show that mother's fertility is not associated with childless woman's fertility intention, but with higher parity woman. Women with many siblings tend to have more children. This finding supports the presence of intergenerational transmission of family norm in Indonesia.
\end{abstract}

Keywords: Indonesia, intergenerational transmission, family size norm, fertility intention, zero-inflated Poisson

JEL classification: J10, J13

\section{Introduction}

There is a substantial body of literature exploring the relationship between mothers' fertility and daughters' fertility intention in developed countries, yet, it remains under researched in developing countries (Murphy, 2013). The result shows a positive relationship, that is, children born with many siblings tend to have many children (e.g. Testa, Bordone, Osiewalska, \& Skirberkk, 2016). Moreover, these studies also consistently show that fertility intention and fertility behaviour are transmitted from parents to their children (Fernandez \& Fogli, 2006; Kotte \& Ludwig, 2011).

According to Montgomery and Casterline (1996), there are two ways how fertility is transmitted across generation. First, it is through social learning where parents can teach about fertility norm directly to their children or children learn indirectly

a Graduate Program of Population Economics and Labour Studies, Faculty of Economics and Business, Universitas Indonesia. Email: purnama@bps.go.id, pur766hi@gmail.com

b Graduate Program of Population Economics and Labour Studies, Faculty of Economics and Business, Universitas Indonesia. Email: diahhadi.s@ui.ac.id, dsetyonaluri@gmail.com (Corresponding Author)

Article Info: Received 1 October 2017; Revised 11 March 2018; Accepted 14 March 2018 
through observation by experiencing living with their family. Second, it is through social influence where there is a diffusion of family size norms within the society. It is worth noting that the continuity of fertility behaviour transmission across generation plays an important role in determining fertility rate (Kumar, Bordone, \& Muttarak, 2016; Murphy \& Knudsen, 2002). Harkness and Super (2002) argued that the pattern of culture is one of the transmissions across generation in traditional societies and family is a culture bearing unit (Glassman \& Eisikovits, 2006). On the other hand, in contemporary societies, where fertility rate is low and contraceptives have been widely spread, the demand for children is based on the cost and benefit of childbearing (Becker, 1981; Becker \& Barro, 1988) and culture only serves as another background in fertility studies (Billari, Philipov, \& Testa, 2009).

In Indonesia, the change in family norms has been argued to be one of the key factors determining its rapid fertility transition. Such transition was contributed by the massive family planning program implemented at the end of the 1970s that promotes the ideation of small family size and contraceptive use. The efforts had successfully halved the fertility rate from 5.71 in 1971 to 2.27 children per woman in 2000 (Statistics Indonesia, 2014); despite that it turned into a stalling rate at around 2.6 children per woman between 2007 and 2012 (Statistics Indonesia, National Population and Family Planning Board, Ministry of Health \& ICF International, 2013). The family planning program was claimed as one "massive coercive act" (Adioetomo, Burhan, \& Yunus, 2009) given that such a program was initiated under the authoritarian regime of the New Order government. Shiffman (2004) argued that the implementation of the program was top-down and motivated by strong political orientations. It involved different agencies up to the village level, including the women family planning group who argued that it became "subtle forms of social pressure" for married women to use the contraception (Shiffman, 2004). The campaign has been claimed to be a success with the small family norm becoming institutionalised as indicated in the high demand for contraceptive use particularly among younger women for birth spacing up until the end of the 1990s (Adioetomo, 2005).

Numerous studies exploring population dynamics found that women's ideal number of children has been shifted downward across cohort (Adioetomo, 1993). The increasing number of educated women in Indonesia (Table 1) has been acknowledged to increase their power to decide their own childbearing behaviour.

Table 1. The percentage of women aged 15 years old and above by level of education attainment, 2009-2015

\begin{tabular}{lccccccr}
\hline Level of education attainment & 2009 & 2010 & 2011 & 2012 & 2013 & 2014 & 2015 \\
\hline \multicolumn{1}{c}{$(1)$} & \multicolumn{1}{c}{$(2)$} & \multicolumn{1}{c}{$(3)$} & \multicolumn{1}{c}{$(4)$} & \multicolumn{1}{c}{$(5)$} & $(6)$ & (7) & $(8)$ \\
\hline Elementary school and lower & 55.38 & 53.15 & 53.09 & 51.35 & 51.47 & 49.73 & 49.38 \\
Junior high school & 38.49 & 40.23 & 40.22 & 41.70 & 41.59 & 42.76 & 42.70 \\
Senior high school and above & 6.13 & 6.62 & 6.67 & 6.96 & 6.94 & 7.52 & 7.92 \\
\hline Total & 100.00 & 100.00 & 100.00 & 100.00 & 100.00 & 100.00 & 100.00 \\
\hline
\end{tabular}

Source: Statistics Indonesia, National Socio-Economic Survey (Susenas), (2009-2015). 


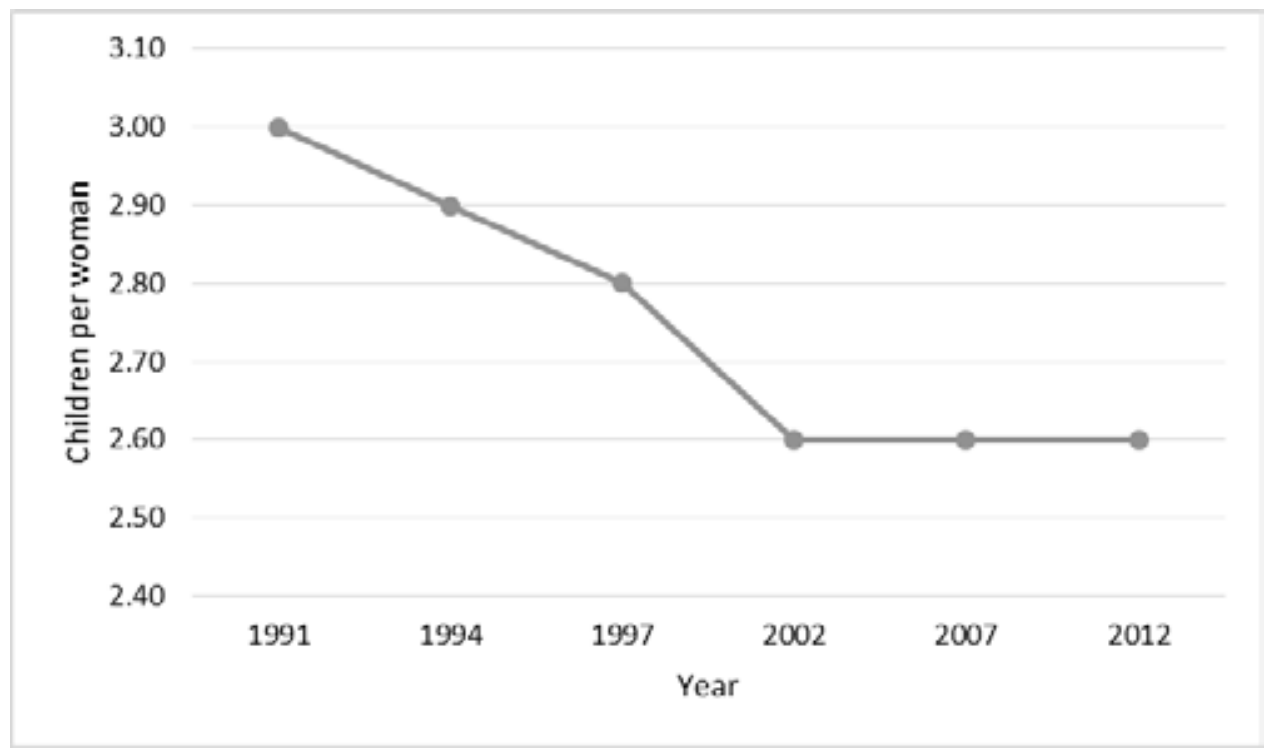

Figure 1. Total fertility rate (TFR) of Indonesia, 1991-2012

Source: Statistics Indonesia, National Population and Family Planning Board, Ministry of Health, and ICF International (2013)

Figure 1 shows that for the last decade, the fertility rate in Indonesia remains at 2.6 children per woman. According to empirical evidence derived from the 2012 Indonesia Demography and Health Survey (IDHS) data, around 40 percent of women in the sample prefer to have more than two children, which implies that some women still adopt a large family norm. Therefore, this study contributes to the existing literature by providing an alternative explanation over the stalling fertility rate phenomenon in Indonesia by identifying the presence of intergenerational transmission of family norm. This study is also focused on the female generation since mother plays a more important role in the transmission of fertility behaviour than the father (Axinn, Clarkberg, \& Thornton, 1994) and mother discusses reproductive issues more often with her daughter rather than son (Remez, 2003).

\subsection{Fertility Intention and Fertility Behaviour}

Fertility intention is often used in studies on fertility since it provides both a better understanding of childbearing behaviour and more accurate prediction of fertility rate in the short or medium run (Philipov, 2011, p. 38). The term intention means a strong determination to act (Fischbein \& Ajzen, 2010; Miller, 2011), whereas fertility behaviour refers to childbearing (Ajzen \& Klobas, 2013). Intention regarding future fertility determines subsequent reproductive behaviours (Schoen, Astone, Young, Nathanson, \& Fields, 1999); that is, when intention changes, so does the behaviour (Ajzen \& Klobas, 2013; Philipov, 2011). 
Despite having been argued as a better indicator, childbearing intention is not equivalent to actual fertility behaviour (Liefbroer, 2009; Philipov, 2009; Schoen et al., 1999). Intention will become more accurate in predicting actual childbearing behaviour if its realisation occurs in the short term (Philipov, Speder, \& Billari, 2006; Schoen et al., 1999). Since an individual's socio-economic situation may change depending on several factors, such as marital status, occupational status, health condition, parenting and childbearing experiences (Reigner-Liolier, 2006), the sooner the intentions are fulfilled, the more likely the goal (having a child) will be attained (Miller \& Pasta, 1995). Moreover, for instance, Ajzen and Klobas (2013) explained that although a couple intend to have a/another child and regularly engage in sexual intercourse but if one of them is infertile, or if miscarriage occurs, they will not end with having a/another child.

This study is based on the theory of planned behaviour (TPB), which was constructed by Ajzen and Klobas (2013). Childbearing intention is determined by three main factors, such as attitudes, subjective norms and perceive controls, while background factors may directly/indirectly lead to the formation of fertility intention by influencing behaviour belief, normative belief, and the belief of enabling factors which affect those main determinants. Behaviour belief is driven by what someone believes about positive and negative consequences of having a child. Miller (1995) explains that when a woman believes that having a child will please her partner/will only create a burden to her career, then she will form a positive/a negative attitude which will influence her reproductive intention. Normative belief is constructed by social pressures or subjective norms toward having a child. It also refers to what partner, parents, or peers want a woman to do, in which it is different from a behaviour belief. The difference between these two terms can be seen in the following sentences: "My partner would be happy if I am pregnant" is a behaviour belief, whereas "My partner wants me to get pregnant" is an injunctive normative belief. Additionally, the formation of a descriptive normative belief is driven by observations from society, such as the number of siblings or the close friend's number of children.

Perceived control is determined by an individual's belief about the availability of resources or facilitation over having a child, such as housing, income or childcare. For instance, the availability of rooms in the house to accommodate an additional member of the family will influence the decision whether or not a couple will have a/another child. Furthermore, Ajzen and Klobas (2013) explained that actual control behaviours mediate the effect of fertility intention on fertility behaviour (i.e., when a woman has a negative fertility intention, she will use contraceptives method as a control behaviour to prevent a pregnancy).

Previous studies have found that fertility intention is influenced by individual and family characteristics. Number of siblings and women's socio-economic characteristics are important determinants of a woman's fertility intention (Ajzen \& Klobas, 2013; Billari, Philipov, \& Testa, 2009).

Number of siblings has been found to have a significant and positive effect on fertility intention where women born in a large family tend to have the same family size as their parents (Kotte \& Ludwig, 2011; Murphy \& Knudsen, 2002; Murphy \& Wang, 2001). However, a study by Kumar, Bordone and Muttarak (2016) as well as Testa et al. (2016) found that daughter's family size preferences are not associated with mother's 
fertility but rather with the mother's level of education attainment. In this study, number of siblings is expected to be positively associated with womens' childbearing intention which indicate that family norms is transmitted from their mothers.

In regard to education, Testa et al. (2016, p. 581) argued that unlike actual childbearing, education is frequently found to have a positive effect on reproductive intention. The postponement of childbearing could be the reason to this positive fertility intention particularly among the educated women. It is common that highly educated women are able to get a better job and gain a higher income, thus they perceive that they could overcome the cost of childrearing (Gauthier, 2007; Tanskanen \& Rotkirch, 2014). However, Cochrane and Guilkey (1992) found that there is no significant difference across education level in determining the fertility intention. This reason may be more appropriate in the context of a developed country, however, this study expects that mother's and daughter's education have a positive effect on their daughter's fertility behaviour.

Reigner-Loilier (2006) also argued that intention to have a/another child may change depending on economic situation (i.e., the number of children intended may shift downward when women are being inactive in the labour market). Moreover, Testa et al. (2016) found that mother's working status when her daughter was a teenager is not statistically significant with either their daughter's zero-child intention or daughter's intended family size.

Changing personal relationships also influences fertility preference. Findings from Qu, Weston and Kilmartin (2000), Reed and McBroom (1995), and Testa and Toulemon (2006) showed that changing relationship status affect the number of children intended with those who had a marriage break up tending to have a lower intention to have children. Marriage dissolution is not only creating unfavourable economic condition to have children but also changing the value of marriage and children (Reed \& McBroom, 1995).

Steenhof and Liefbroer (2008) revealed that children's age has an inverse relationship with the intergenerational transmission effect. The tendency to have more children is stronger for younger women than for older women (Billari et al., 2009). Younger women might still have a longer reproductive span and expect to have an additional child as compared to their older counterparts. Meanwhile, for co-residence status, Snopkowski and Sear (2016) found that living co-residence with mother is positively associated with their daughter's childbearing behaviour.

Some researchers found that the strength of the intergenerational transmission is varied across cohorts. Murphy and Wang (2001), comparing the completed fertility of two successive generations, argued that the effect of intergenerational transmission of fertility is strong. Parents continue to affect their children's preferences even when their children enter adulthood (Axinn et al., 1994). Barber (2000) emphasised that the relationship between mother and daughter depends on their closeness (i.e. the closer a woman to her mother, the higher the probability she will resemble her mother's behaviour). On the contrary, Stolzenberg and Waite (1977) argued that children's maturity and experiences in adulthood may change their family size preference to become more realistic and thus parental effect becomes weaker. 


\section{Data and Methods}

\subsection{Data Source}

This study uses data from the 2014 Indonesian Family Life Survey (IFLS) since it provides data related to an individual's fertility. The IFLS is a large-scale longitudinal survey which had been conducted for more than 21 years and represents about 83 percent of the population in Indonesia. The sample unit of this study is women aged 15-49 years old in 2014 who have information about their fertility intention and complete information about their birth mother. Women who is unmarried, those who have stopped menstruation, those who have been sterilized, and those who said "up to God" in their fertility intention are excluded from the sample. The missing data are also deleted from the data set and thus the final sample consists of 7,635 women.

The sample is also stratified by women's number of children (parity); that is, parityzero (childless), parity-one, parity-two and above. With respect to parity, the intention to have the first child is an intention to become a parent (Hobcraft \& Kiernan, 1995). In addition, Miller (2011) argued that for childless women, their desires to have a child can directly influence their reproductive behaviour. Whilst, for higher parity women, the intention to have an additional child is driven by their experiences of parenthood (Billari et al., 2009; Dommermuth, Klobas, \& Lappegard, 2011). Women of one child, as compared to those who already have two or more children, are more likely to have another child (Balbo \& Mills, 2011; Taskanen \& Rotkirch, 2014).

The dependent variable in this study is fertility intention (numeric), which is derived from the question "How many (more) children do you wish to have?" The explanatory variables are mother's years of schooling (numeric), mother's working status when the women were at age 15-19 years old (i.e., working, intermittent, and not working as reference), women's years of schooling (numeric), and the number of siblings (numeric) which represents maternal fertility behaviour. It is important to note that mother's working status when the women were at adolescence age is measured using the mother's current working status for women who are non-coresident with their mothers due to limitation of the data. Other control variables in this study are women's characteristics, such as age (numeric), marital status (married and separated/divorced/ widowed as reference), working status (working and not working as reference), and coresidence status (living co-residence with mother and living separately from mother or mother died as reference).

\subsection{Methods}

The main method used in this study is zero-inflated Poisson (ZIP) regression model which is adapted from Testa et al. (2016), particularly for high parity women. This method is used because there are many women who reported that they did not intend to have a/another child, thus the standard Poisson model cannot deal with excessive zero numbers in the variable. This study uses STATA 14 statistical software to run the ZIP regression model. However, for childless women, the sample distribution shows a low proportion of zero intention. Therefore, we use logistic regression model instead of ZIP. Instead of focusing on their intention to have children, the interpretation of 
odds ratio for childless women from the logistic model is similar to that of zero model generated in ZIP regression model. This approach is taken given that marriage is universal and is undertaken for the reason of procreation in Indonesia. This is related to the stigma given to both voluntary and involuntary childless women where they are seen as being incomplete and cannot acknowledge their status as a family in the society (Bennet, 2018).

A large number of zero child intended may occur since not all women answered a positive fertility intention (Osiewalska, 2013). It is possibly because they are infertile (certain zero), they decided to remain childless, or they have completed their ideal family size (Miller, 2011). Additionally, as stated by Reigner-Loilier (2006), the number of children intended is dynamic; it may decrease due to marriage break-up, inactive in the labour market, or negative experiences from childbearing and parenting.

There are two types of individuals examined in ZIP regression model, that is, those who always have zero count, i.e., those who are infertile (certain zero group) and those who are not always having zero intention. ${ }^{1}$ Those from the second group refers to women who reported to not intending to have a/another child under some circumstances, but still like to have a/another child sometime. Lambert (1992) explained that the probability of this sample unit to be part of zero model is $\omega_{i}$, (i.e., estimated by the logit model), while expected number of children intended is predicted by the standard Poisson model $\left(\lambda_{\mathrm{i}}\right)$. Both models generated in ZIP regression model are connected by the probability $1-\omega_{i}$ (Testa et al., 2016). Noting that when the zero-child intention comes from those in the certain zero group, it implies that they are free from the probability of having a positive fertility intention (Long, 1997). The coefficients in each model are interdependent but they should be interpreted respectively by each model (Testa et al., 2016). The probabilities to be in part of zero and count model are shown in the following equations.

$$
\operatorname{Pr}\left(\mathrm{Y}_{i}=\mathrm{y}_{i}\right)=\left\{\begin{array}{ll}
\omega_{i}+\left(1-\omega_{i}\right) \exp \left(-\lambda_{i}\right), & y_{i}=0 \\
\left(1-\omega_{i}\right) \exp \left(-\lambda_{i}\right) \lambda_{i}^{y_{i}} / y_{i} !, & y_{i}>0
\end{array}\right\}
$$

From Equation 1, since ZIP combines two regression models, thus ZIP is constructed by the following equation.

$$
\log (\lambda)=X \beta \text { and } \log \omega=Z \gamma
$$

where $X$ and $Z$ are matrices of predictors, while $\beta$ and $\gamma$ are the estimates of count model and zero model, respectively.

According to Testa et al. (2016, p. 598), odds ratios (OR) generated by the logit model indicate the effects of predictors on zero-child intention. Given that other variables in the model are constant, OR greater than 1 indicates a positive effect of the predictors on the zero-child intention, whereas OR smaller than 1 indicates otherwise.

1 In this study, the sample of women who answered as having zero-child intention includes those who are infertile (i.e., self-identifying as physically unable to conceive a child with or without meeting medical help). A similar study which also includes such a sample can be seen, for example, in Shreffler et al. (2016). 
OR with a value of more than 1 indicates that the odds to have zero-child intention is higher for one property as compared to the other. Meanwhile, the result of the standard Poisson model are presented as risk ratios (RR) that indicates the probability of predictors to have non zero-child intention. RR greater than 1 indicates higher preferences to have a large family size; while RR smaller than 1 indicates otherwise, holding other variables in the model are constant.

This study constructs three models: Model I consists of the number of siblings and other control variables, Model II adds mother's working status at women's adolescence age (15-19 years old), women's and their mother's years of schooling, Model III includes all variables in the model. This modelling aims to analyse the difference of the magnitude effect of key explanatory variables after controlling for other variables.

\section{Results}

As mentioned earlier, for childless women, a fertility intention refers to the number of children they intend to have, whereas for those in the higher parity groups, it refers to have another child. Table 2 shows that on average, women in the sample with higher years of schooling than their mothers have an average number of siblings of 3.9 while the average age is 32.67 years old.

Table 2. Descriptive statistics of women's education, mother's education, number of siblings and age

\begin{tabular}{ccccc}
\hline \multicolumn{1}{c}{ Variables } & Mean & Std. Err. & Min & Max \\
\hline (1) & $(2)$ & $(3)$ & $(4)$ & $(5)$ \\
\hline Years of schooling & 9.84 & 3.76 & 0 & 20 \\
Mother's years of schooling & 6.05 & 3.54 & 0 & 20 \\
Number of siblings & 3.93 & 2.06 & 1 & 17 \\
Age & 32.67 & 7.75 & 15 & 49 \\
\hline
\end{tabular}

Source: Authors' calculation from IFLS of various years.

As shown in Table 3, the highest percentage of women intending to have at least two additional child are those who are in parity-one group. A majority of women with three or more siblings are those who have two or more children. The highest share of women whose mother was working when they were aged 15-19 years old are those who are in parity two or above. Furthermore, the highest share of women participating in the labour market are those in parity two and above, while most women who are not working are those with one child. Most of the women who are living separately from their mother have one child, whereas the highest percentage of those who are co-resident with their mother are in parity two and above group. A majority of married women are in parity-one, while the highest share of those who are separated/ widowed/divorced are women in the higher parity group. 
Table 3. Cross tabulation between women's parity groups and explanatory variables

\begin{tabular}{|c|c|c|c|c|}
\hline \multirow[t]{2}{*}{ Variable } & \multicolumn{3}{|c|}{ Parity } & \multirow[t]{2}{*}{ Total } \\
\hline & 0 & 1 & $2+$ & \\
\hline (1) & (2) & (3) & (4) & (5) \\
\hline \multicolumn{5}{|l|}{ Fertility intention } \\
\hline 0 & 1.28 & 31.02 & 67.71 & 3524 \\
\hline 1 & 2.9 & 67.09 & 30.01 & 2416 \\
\hline $2+$ & 37.76 & 44.9 & 17.35 & 1695 \\
\hline \multicolumn{5}{|l|}{ Number of Siblings } \\
\hline 1 & 9.59 & 45.51 & 44.90 & 657 \\
\hline 2 & 12.92 & 48.74 & 38.33 & 1393 \\
\hline $3+$ & 9.17 & 44.71 & 46.12 & 5585 \\
\hline \multicolumn{5}{|l|}{$\begin{array}{l}\text { Mother's working status at women's } \\
\text { adolescent age }\end{array}$} \\
\hline Not working & 11.48 & 44.26 & 44.26 & 61 \\
\hline Intermittent & 10.22 & 46.55 & 43.22 & 3845 \\
\hline Working & 9.52 & 44.46 & 46.02 & 3729 \\
\hline \multicolumn{5}{|l|}{ Working status } \\
\hline Not working & 8.55 & 47.19 & 44.25 & 4384 \\
\hline Working & 11.69 & 43.25 & 45.06 & 3251 \\
\hline \multicolumn{5}{|l|}{ Co-resident status of mother } \\
\hline Living separately/Died & 9.42 & 47.47 & 43.11 & 5778 \\
\hline Living co-resident & 11.36 & 39.42 & 49.22 & 1857 \\
\hline \multicolumn{5}{|l|}{ Marital status } \\
\hline Separated/Divorced/Widowed & 7.99 & 45.36 & 46.65 & 388 \\
\hline Married & 9.99 & 45.52 & 44.49 & 7247 \\
\hline Total & 9.89 & 45.51 & 44.60 & 7635 \\
\hline
\end{tabular}

Source: Authors' calculation from IFLS of various years.

The mean of intended family size (Table 4) is calculated as the sum of women's number of children and their fertility intention. On average, for parity two and above women, those who have no siblings intend to have 3.03 children, those with one sibling intend to have 2.87 children, while those coming from a large family intend to have 2.97 children. Among childless and parity-one women, it has an inverse relationship with the

Table 4. Mean of intended family size by women's parity

\begin{tabular}{cccc}
\hline Number of Siblings & \multicolumn{3}{c}{ Parity } \\
\cline { 2 - 4 } & 0 & 1 & $2+$ \\
\hline$(1)$ & $(2)$ & $(3)$ & $(4)$ \\
\hline 0 & 2.33 & 2.04 & 3.03 \\
1 & 2.31 & 2.04 & 2.87 \\
$2+$ & 2.19 & 1.99 & 2.97 \\
\hline
\end{tabular}

Source: Authors' calculation from IFLS of various years. 
number of siblings, while for higher parity women, it has a U-shape relationship with the number of siblings (i.e., mean of intended family size declines as the number of siblings increases, but then reshift upward for those with two or more siblings).

The results of logistic regression for parity-zero women (Table 5) show there is no relevant differences of all key explanatory variables found in the preference of childless women's fertility intention (i.e. their intention is more influenced by their own characteristics, such as age, working status and marital status). As explained by Hobcraft and Kiernan (1995), their intention to have a child is driven by their desire to become a mother. Age has a positive effect on reproductive intention of women with zero parity; that is, as the women get older, their probability of zero-child intention gets higher. This is possibly due to the shorter reproductive span of the older women.

Table 5. The odds ratio of zero child intention from logistic regression model for childless women

\begin{tabular}{lccc}
\hline \multicolumn{1}{c}{ Variable } & Model I & Model II & Model III \\
\hline \multicolumn{1}{c}{$(1)$} & $(2)$ & $(3)$ & $(4)$ \\
\hline $\begin{array}{l}\text { Number of siblings } \\
\text { Mother's years of schooling }\end{array}$ & 0.948 & & 0.951 \\
Mother's working status at women's & & 1.004 & 1.003 \\
adolescent age & & & \\
$\quad$ Working & & 0.872 & 0.877 \\
$\quad$ Intermittent & & 0.648 & 0.658 \\
Years of schooling & 1.045 & 1.046 & 1.046 \\
Age & $1.087^{* * *}$ & $1.083^{* * *}$ & $1.088^{* * *}$ \\
Working status & $0.436^{* *}$ & $0.448^{* *}$ & $0.440^{* *}$ \\
Co-resident status with mothers & 0.961 & 0.938 & 0.942 \\
Marital status & $0.138^{* * *}$ & $0.140^{* * *}$ & $0.139^{* * *}$ \\
Constant & $0.034^{* * *}$ & $0.039^{* *}$ & $0.041^{*}$ \\
\hline
\end{tabular}

Note: ${ }^{*} \mathrm{p}<0.1,{ }^{* *} \mathrm{p}<0.05,{ }^{* * *} \mathrm{p}<0.01$.

Working status has a negative effect on parity-zero women's childbearing intention. Being active in the labour market decreases the probability of zero-child intention. The perception to be able to anticipate the cost of childbearing and childrearing by working determines their decision to have one child or more. Moreover, marital status is negatively related to childless women's reproductive intention. Married women have lower probability to be childless, as compared to those who do not have a partner. Miller (1995) explained that when a woman believes that a child would bring happiness to her marriage life, she will have a positive fertility intention.

According to the results of zero-inflated Poisson (ZIP) regression model, on the part of zero model (Table 6), for parity-one women, almost all maternal variables have a negative effect on zero child intention, except the number of siblings. Meanwhile, women's education is significantly related to their number of children intended after controlling for other variables. 
Table 6. The odds ratio of no child intention for higher parity women (zero part of the zero-inflated Poisson model)

\begin{tabular}{|c|c|c|c|c|c|c|}
\hline \multirow{2}{*}{ Variable } & \multicolumn{3}{|c|}{ Parity one } & \multicolumn{3}{|c|}{ Parity two and above } \\
\hline & Model I & Model II & Model III & Model I & Model II & Model III \\
\hline (1) & (2) & (3) & (4) & (5) & (6) & (7) \\
\hline Number of siblings & 0.990 & & 1.018 & 1.066 & & 1.064 \\
\hline Mother's years of schooling & & $0.879^{* *}$ & $0.880^{* *}$ & & 1.024 & 1.022 \\
\hline \multicolumn{7}{|l|}{$\begin{array}{l}\text { Mother's working status at } \\
\text { women's adolescent age }\end{array}$} \\
\hline Working & & $0.039^{*}$ & $0.036^{*}$ & & 1.193 & 1.056 \\
\hline Intermittent & & $0.022^{* *}$ & $0.020^{*}$ & & 1.351 & 1.202 \\
\hline Years of schooling & 1.018 & 1.068 & $1.075^{*}$ & 0.967 & 0.962 & 0.958 \\
\hline Age & $1.388^{* * *}$ & $1.408^{* * *}$ & $1.411^{* * *}$ & $1.214^{* * *}$ & $1.220^{* * *}$ & $1.215^{* * *}$ \\
\hline Working status & 1.272 & 1.037 & 1.053 & 1.062 & 1.111 & 1.102 \\
\hline Co-resident status with mother & $0.056^{* * *}$ & $0.035^{* * *}$ & $0.031^{* * *}$ & 0.910 & 0.969 & 0.968 \\
\hline Marital status & 0.382 & 0.372 & 0.379 & 0.782 & 0.814 & 0.772 \\
\hline Constant & $0.000^{* * *}$ & $0.000^{* * *}$ & $0.000^{* * *}$ & $0.001^{* * *}$ & $0.001^{* * *}$ & $0.001^{* * *}$ \\
\hline
\end{tabular}

Note: ${ }^{*} \mathrm{p}<0.1,{ }^{* *} \mathrm{p}<0.05,{ }^{* * *} \mathrm{p}<0.01$.

As shown in Table 7, the effects of most predictors in count model are positive and strong for parity-one women rather than for those in the higher parity group. This finding is consistent with prior studies where women of one child have higher probability to have another child, as compared to those who have two or more children (Balbo \& Mills, 2011; Taskanen \& Rotkirch, 2014). The regression result of complete model (see Model III in Tables 5 and 6), shows that number of siblings has no effect on zero-child intention but is positively and significantly associated with women's number of children intended in all high parity groups. This positive effect is stronger for parityone women than for those in higher parity group. Being born in a large family increases the probability to adopt the same family norm as their mother, which means that highparity women with many siblings tend to have more children (e.g., Testa et al., 2016). This positive association also supports the presence of intergenerational transmission of family norm from mother to daughter in the sample. The effect of mother's fertility behaviour on women's fertility intention is robust in all high-parity groups even after controlling for other variables, while mother's socio-economic characteristics are not statistically associated. Women's years of schooling has a strong and persistent effect on number of children intended only for parity-one women, whereas in parity two and above, education has no significant effect. With respect to education, women's years of schooling is positively significant only in count model of parity-one women. This result implies that the higher the education, the more likely the women in parity-one group prefer a large family size, as compared to their counterparts with lower level of education. As explained by Testa et al. (2016), highly educated women may gain 
Table 7. Risk ratios of intention to have given number of children for higher parity women (count part of the zero-inflated Poisson model)

\begin{tabular}{|c|c|c|c|c|c|c|}
\hline \multirow{2}{*}{ Variable } & \multicolumn{3}{|c|}{ Parity one } & \multicolumn{3}{|c|}{ Parity two and above } \\
\hline & Model I & Model II & Model III & Model I & Model II & Model III \\
\hline (1) & (2) & (3) & (4) & (5) & (6) & (7) \\
\hline Number of siblings & $1.047^{* * *}$ & & $1.048^{* * *}$ & $1.038^{* *}$ & & $1.037^{*}$ \\
\hline Mother's years of schooling & & 0.998 & 0.999 & & 1.008 & 1.007 \\
\hline \multicolumn{7}{|l|}{$\begin{array}{l}\text { Mother's working status at } \\
\text { women's adolescent age }\end{array}$} \\
\hline Working & & 1.305 & 1.305 & & 0.908 & 0.878 \\
\hline Intermittent & & 1.290 & 1.272 & & 1.010 & 0.974 \\
\hline Years of schooling & $1.014^{* *}$ & $1.012^{* *}$ & $1.014^{* *}$ & 0.989 & 0.986 & 0.986 \\
\hline Age & $0.969^{* * *}$ & $0.973^{* * *}$ & $0.969^{* * *}$ & $0.983^{* * *}$ & $0.984^{* *}$ & $0.982^{* * *}$ \\
\hline Working status & 1.019 & 1.006 & 1.010 & $1.324^{* * *}$ & $1.352^{* * *}$ & $1.347^{* * *}$ \\
\hline Co-resident status with mother & $1.091^{* *}$ & $1.075^{*}$ & $1.095^{* *}$ & 1.060 & 1.074 & 1.082 \\
\hline Marital status & 1.066 & 1.047 & 1.056 & 1.305 & 1.316 & 1.295 \\
\hline Constant & $1.847^{* * *}$ & $1.618^{*}$ & 1.447 & 0.834 & 0.920 & 0.905 \\
\hline
\end{tabular}

Note: ${ }^{*} \mathrm{p}<0.1,{ }^{* *} \mathrm{p}<0.05,{ }^{* * *} \mathrm{p}<0.01$.

higher income and perceivably more secure financially to deal with the high cost of childbearing and childrearing. Meanwhile, there are no relevant differences of mother's years of schooling and mother's working status at women's adolescence age found in the preference of high parity women's fertility intention (i.e., their intention is more influenced by their mother's fertility behaviour).

Among other control variables, age is the strongest determinant that also persistently affects high-parity women's fertility intention in either model. Age has a positive effect on zero-child intention but has a negative association with the number of children intended. This result is parallel with the finding of Billari et al. (2009) where younger women intend to have more children. This is possibly due to their longer reproductive span.

Participation in the labour market has a positive effect on the preference for a larger family size, as compared to those who do not participate in the labour market, i.e. working women intend to have more children. Reigner-Loilier (2006) found that being employed may increase the number of children intended. It may be due to the ability to attain higher assets which enable them to anticipate the opportunity cost of childrearing, as compared to those who are inactive in the labour market.

Mother-daughter co-resident status has a negative effect on zero-child intention but positively influences parity-one women's number of children intended. Residing with their mother increase the probability of preferring a large family size. This result confirms the finding of Snopkowski and Sear (2016) in Indonesia, that residing with mother is positively associated with women's childbearing behaviour. 


\section{Discussion and Conclusion}

According to the aim of this study, the finding supports the presence of intergenerational transmission of family norm in Indonesia. There are positive relationships between mother's fertility and women's fertility intention, even though this positive association is significant only for high-parity women. It indicates that high-parity women adopt their mothers' family size norm in determining their own fertility intention. It is possibly due to their life-course experiences, having grown up in a large family. While, as found by Miller (2011), an intention to have a child for childless women is more driven by their desire to be a mother than by their mother's fertility behaviour. However, fertility intention is dynamic. Reigner-Liolier (2006) stated that the number of children intended may change due to biological condition, marital status as well as individual's socio-economic situation.

Meanwhile, the effect of mother's socio-economic characteristics, such as education and working status, are negative and significant only for parity-one women in the part of zero model. Women having a highly educated and working mother at age 1519 years old decreases the probability for being childless. This finding also shows that women's fertility intention is more influenced by mother's family size than mother's socio-economic situation.

As mentioned earlier, the continuity of such transmission across generation may influence the fertility rate (Kumar et al., 2016; Murphy \& Knudsen, 2002; Testa et al., 2016). Thus, the government should pay more attention toward the implementation of a family planning program, particularly in promoting the benefit of smaller number of children with the extent to change perception, attitude and reproductive behaviour. The benefit of fewer children is not only related to the welfare of the family, but also to the society in general (Canning, Mitchell, Bloom, \& Kleindorfer, 1994). Children from a smaller family have better quality of life in terms of more household resources allocated for their human capital development as compared to children from larger families. Parents with fewer children also have the advantage of more resources for food, health and time in the labour market. In the long term, a small family size helps the economy not just by reducing population growth, but also improving the economy through improvement in quality of the people.

Due to data limitation, this study has a limitation in measuring attitudes, subjective norms and perceived control as indicated in Azjen and Klobas' (2013) "Theory of planned behaviour", given such information are not available in the data. This means that the framework that suggests the indirect effect of individuals' socio-demographic characteristics on fertility intentions through changing beliefs which further affect attitudes, norms and perceived control could not be fully explored.

\section{References}

Adioetomo, S. (1993). The construction of a small-family norm in Java (PhD thesis, Australian National University, Canberra, Australia). Retrieved from http://hdl.handle.net/1885/123651

Adioetomo, S. (2005). Reshaping populations. In T. Hull (Ed.), People, population and policy in Indonesia (pp. 125-168). Jakarta: Equinox Publishing. 
Adioetomo, S., Burhan, L., \& Yunus, N. (2009). A century of Indonesia demography: Changing destiny into hope. Jakarta: BKKBN and LD-FEUI.

Ajzen, I., \& Klobas, J. (2013). Fertility intentions: An approach based on the theory of planned behaviour. Demographic Research, 29(8), 203-232. doi: 10.4054/DemRes.2013.29.8

Axinn, W.G., Clarkberg, M.E., \& Thornton, A. (1994). Family influences on family size preferences. Demography, 31(1), 65-79. doi: 10.2307/2061908

Balbo, N., \& Mills, M. (2011). The influence of the family network on the realisation of fertility intentions. Vienna Yearbook of Population Research, 9, 179-205. doi: 10.2307/41342810

Barber, J.S. (2000). Intergenerational influences on the entry into parenthood: Mothers' preferences for family and nonfamily behaviour. Social Forces, 79(1), 319-348. doi: 10.2307/ 2675573

Becker, G.S. (1981). A treatise on the family. Cambridge, MA: Harvard University Press.

Becker, G.S., \& Barro, R.J. (1988). A reformulation of the economic theory of fertility. The Quarterly Journal of Economics, 103(1), 1-25. doi: 10.2307/1882640

Bennet, L.R. (2018). Infertility, adoption, and family formation in Indonesia. Medical Anthropology (Advanced online publication). doi: 10.1080/01459740.2017.1407931

Billari, F.C., Philipov, D., \& Testa, M.R. (2009). Attitudes, norms and perceived behavioural control: Explaining fertility intentions in Bulgaria/Attitudes, normes et contrôle perçu du comportement: Une explication des intentions de fécondité en Bulgarie. European Journal of Population/Revue Européenne de Démographie, 25(4), 439-465. doi: 10.1007/s10680-0099187-9

Canning, D., Mitchell, M., Bloom, D., \& Kleindorfer, E. (1994). The family and economic development. Harvard Institute for International Development. Retrieved from http://citeseerx.ist. psu.edu/viewdoc/download?doi=10.1.1.194.8310\&rep=rep1\&type=pdf

Cochrane, S. \& Guilkey, D.K. (1992). How access to contraception affects fertility and contraceptive use in Tunisia (Policy Research Working Paper no. WPS 841). Washington DC: World Bank. Retrieved from http://documents.worldbank.org/curated/en/816561468781762003/ How-access-to-contraception-affects-fertility-and-contraceptive-use-in-Tunisia

Dommermuth, L., Klobas, J., \& Lappegard, T. (2011). Now or later? The theory of planned behaviour and timing of fertility intentions. Advances in Life Course Research, 16(1), 42-53. doi: 10.1016/j.alcr.2011.01.002

Fernandez, R., \& Fogli, A. (2006). Fertility: The role of culture and family experience. Journal of the European Economic Association, 4(2/3), 552-561. doi: 10.3386/w11569

Fischbein, M. and Ajzen, I. (2010). Predicting and changing behaviour: The reasoned action approach. New York: Psychology Press.

Gauthier, A.H. (2007). The impact of family policies on fertility in industrialized countries: A review of the literature. Population Research and Policy Review, 26(3), 323-346. doi: 10.1007/ s11113-007-9033-x

Glassman, I., \& Eisikovits, R.A. (2006). Intergenerational transmission of motherhood patterns: Three generations of immigrant mothers of Moroccan descent in Israel. Journal of Comparative Family Studies, 37(3), 461-477.

Harkness, S., \& Super, C.M. (2002). Culture and parenting. In M. Bornsten (Ed.), Handbook of parenting (2nd ed.): Vol. 2, Biology and ecology of parenting (pp. 253-280). Mahwah, NJ: Lawrence Erlbaum Associates Inc.

Hobcraft, J., \& Kiernan, K. (1995). Becoming a parent in Europe (Discussion Paper WSP/116, Welfare State Programme). London: The Toyota Centre, London School of Economics.

Kotte, M., \& Ludwig, V. (2011). Intergenerational transmission of fertility intentions and behaviour in Germany: The role of contagion. Vienna Yearbook of Population Research, 9, 207-226. doi: $10.2307 / 41342811$ 
Kumar, A., Bordone, V., \& Muttarak, R. (2016). Like mother (-in-law) like daughter? Influence of the older generation's fertility behaviours on women's desired family size in Bihar, India. European Journal of Population, 32(5), 629-660. doi: 10.1007/s10680-016-9379-z

Lambert, D. (1992). Zero-inflated Poisson regression, with an application to defects in manufacturing. Technometrics, 34(1), 1-14. doi: 10.2307/1269547

Liefbroer, A. (2009). Changes in family size intentions across young adulthood: A life-course perspective. European Journal of Population, 25(4), 363-386. doi: 10.1007/s10680-008-9173-7

Long, J.S. (1997). Regression models for categorical and limited dependent variables. Thousand Oaks, CA: Sage Publications.

Miller, W.B. (1995). Childbearing motivation and its measurement. Journal of Biosocial Science, 27(4), 473-487. doi: 10.1017/S0021932000023087

Miller, W.B. (2011). Differences between fertility desires and intentions: Implications for theory, research and policy. Vienna Yearbook of Population Research, 9, 75-98. doi: 10.2307/ 41342806

Miller, W.B., \& Pasta, D.J. (1995). Behavioural intentions: Which ones predict fertility behaviour in married couples? Journal of Applied Social Psychology, 25(6), 530-555. doi: 10.1111/j.15591816.1995.tb01766.x

Montgomery, M.R., \& Casterline, J.B. (1996). Social learning, social influence, and new models of fertility. Population and Development Review, 22, 151-175. doi: 10.2307/2808010

Murphy, M. (2013). The intergenerational transmission of reproductive behaviour: Comparative perspectives. The History of the Family, 18(2), 107-115. doi: 10.1080/1081602X.2013.808447

Murphy, M., \& Knudsen, L.B. (2002). The intergenerational transmission of fertility in contemporary Denmark: The effects of number of siblings (full and half), birth order, and whether male or female. Population Studies, 56(3), 235-248.

Murphy, M., \& Wang, D. (2001). Family-level continuities in childbearing in low-fertility societies. European Journal of Population, 17(1), 75-96. doi: 10.1023/A:101074431432

Osiewalska, B. (2013). Transmission of fertility pattern in mother-daughter relation: Bayesian view (a case study of Austria). Studia Demograficzne, 1(163), 3-35.

Philipov, D. (2009). The effect of competing intentions and behaviour on short-term childbearing intentions and subsequent childbearing/L'effet des intentions et des comportements concurrents sur les intentions de procréation à court terme et la procréation ultérieure. European Journal of Population/Revue Européenne de Démographie, 25(4), 525-548. doi: 10.1007/s10680-009-9197-7

Philipov, D. (2011). Theories on fertility intentions: A demographer's perspective. Vienna Yearbook of Population Research, 9(1), 37-45. doi: 10.2307/41342801

Philipov, D., Speder, Z., \& Billari, F. (2006). Soon, later, or ever? The impact of anomie and social capital on fertility intentions in Bulgaria (2002) and Hungary (2001). Population Studies, 60(3), 289-308. doi: 10.1080/00324720600896080

Qu, L., Weston, R., \& Kilmartin, C. (2000). Children? No children? Effects of changing personal relationship on decisions about having children. Family Matters, 57, 14-19.

RAND Corporation, \& Lembaga Demografi University of Indonesia. (1995). Indonesia family life survey 1993. Santa Monica, United States: RAND Corporation. Retrieved from https://www. rand.org/labor/FLS/IFLS/download.html

RAND Corporation, \& Lembaga Demografi Universitas Indonesia. (2000). Indonesia family life survey 1997. Santa Monica, United States: RAND Corporation. Retrieved from https://www. rand.org/labor/FLS/IFLS/download.html

RAND Corporation, \& Center for Population and Policy Studies (CPPS) of the University of Gadjah Mada. (2004). Indonesia family life survey 2000. Santa Monica, United States: RAND Corporation. Retrieved from https://www.rand.org/labor/FLS/IFLS/download.html 
RAND Corporation, Center for Population and Policy Studies (CPPS) of the University of Gadjah Mada, \& Survey Meter. (2009). Indonesia family life survey 2007. Santa Monica, United States: RAND Corporation. Retrieved from https://www.rand.org/labor/FLS/IFLS/download. html

RAND Corporation, \& Survey Meter. (2016). Indonesia family life survey 2014. Santa Monica, United States: RAND Corporation. Retrieved from https://www.rand.org/labor/FLS/IFLS/ download.html

Reed, F., \& McBroom, W. (1995). Impact of marriage on fertility intentions and related values. International Journal of Sociology of the Family, 25(1), 91-98.

Reigner-Loilier, A. (2006). Influence of own sibship size on the number of desired at various times of life: The case of France. Population, 61(3), 165-194. doi: 10.3917/popu.603.0193

Remez, L. (2003). Mothers exert more influence on timing of first intercourse among daughters than among sons. Perspectives on Sexual and Reproductive Health, 35(1), 55. doi: 10.1363/ 3505503

Schoen, R., Astone, N.M., Young, J.K., Nathanson, C.A., \& Fields, J.M. (1999). Do fertility intentions affect fertility behaviour? Journal of Marriage and Family, 61(3), 790-799. doi: $10.2307 / 353578$

Shiffman, J. (2004). Political management in the Indonesian family planning program. International Perspectives on Sexual and Reproductive Health, 30(1), 27-33. Retrieved from: https:// www.guttmacher.org/journals/ipsrh/2004/03/political-management-indonesian-family-planning-program

Shreffler, K., Tiemeyer, S., Dorius, C., Spierling, T., Greil, A., \& McQuillan, J. (2016). Infertility and fertility intentions, desires, and outcomes among US women. Demographic Research, 35(1), 1149-1168. doi: 10.4054/DemRes.2016.35.39

Snopkowski, K., \& Sear, R. (2016). Does grandparental help mediate the relationship between kin presence and fertility? Demographic Research, 34(17), 467-498. doi: 10.4054/DemRes. 2016.34.17

Statistics Indonesia. (2014). Table 1: Total fertility rate (TFR) by province 1971, 1980, 1990, 1991, 1994, 1997, 2000, 2002, 2007, 2010, and 2012. Retrieved from https://www.bps.go.id/ statictable/2009/02/20/1271/angka-fertilitas-total-menurut-provinsi-1971-1980-1985-19901991-1994-1997-1998-1999-2000-2002-2007-2010-dan-2012.html

Statistics Indonesia (Badan Pusat Statistik-BPS). (various years). National socio-economics survey. Jakarta, Indonesia: Author.

Statistics Indonesia (Badan Pusat Statistik-BPS), National Population and Family Planning Board (BKKBN), Kementerian Kesehatan (Kemenkes-MOH), \& ICF International. (2013). Indonesia demographic and health survey 2012. Jakarta, Indonesia: Authors.

Steenhof, L., \& Liefbroer, A.C. (2008). International transmission of age at first birth in Netherlands for birth cohorts born between 1935 and 1974: Evidence from municipal registers. Population Studies, 62(1), 69-84. doi: 10.1080/00324720701788616

Stolzenberg, R.M., \& Waite, L.J. (1977). Age, fertility expectations and plans for employment. American Sociological Review, 42(5), 769-783. doi: 10.2307/2094865

Tanskanen, A.O., \& Rotkirch, A. (2014). The impact of grandparental investment on mothers' fertility intentions in four European countries. Demographic Research, 31(1), 1-26. doi: 10.4054/DemRes.2014.31.1

Testa, M.R., Bordone, V., Osiewalska, B., \& Skirberkk, V. (2016). Are daughters' childbearing intentions related to their mothers' socio-economic status? Demographic Research, 35(21), 581-616. doi: 10.4054/DemRes.2016.35.21

Testa, M.R., \& Toulemon, L. (2006). Family formation in France: Individual preferences and subsequent outcomes. Vienna Yearbook of Population Research, 4, 41-75. doi: 10.1553/ populationyearbook2006s41 